\title{
QIKJS-Part.II.D
}

\section{Qualitative Inquiry of Korean Judicial System}

\author{
Kiyoung Kim \\ Professor of Law and Public Policy \\ Dept. of Law, Chosun University \\ Gawng-ju South Korea
}

\section{The Theory and Qualitative Research}

Reeling the research topic and objects to be investigated can only be valid and credible that the theory or literature review is exhausted upon the person over the research operation. As Cooper guides, the literature review and theories importantly interacts through the whole of research process, which is often called an influence in the world of academia (Randolph, 2009). The importance of theory and literature is "explicitly imbrued" with the quantitative method that the researchers benefit from framing his hypothesis to be tested with the public survey and other empirical data. In case of qualitative studies, the theory and literature review has a trait comparatively with the quantitative case, (i) more rigorously read to some extent of exhaustion (recalled that rigor is best covenant to increase the validity and credibility as Patton suggests), (ii) "impliedly imbrued" to color the research (recalled that "discursive" with Foucault's epistemology, more philosophical and on constructivism, and often about the subjectivity, intact cultural group, etc.), and (iii) more resilient and continuing through the end of research (recalled that often quantitative studies had a stronger emphasis of literature review or theory relating with earlier stage of research, i.e., formulation of hypothesis, research questions, the kind of framework elaboration to design the research). Given my method of ground theory approach, the explicit connection with the theory or specific literature is less conceivable except for the kind of grand theory or the literature of philosophical influence (Kim, 2015a,b,c,d). The theory or literature, however, probably allows the time of critical inflection to guide the ethos or theme or stories, and intelligently affects the structure of thesis, argumentation, and tones or metaphor. It also provides the lens of analysis or criticism on the object of research. This general relationship between the theory and qualitative method or grounded theory research, however, would presume a critical reading and thinking through the exhaustive search of relevant literature. To increase the ability of critical reading and thinking, it would be wise to practice a critique of journal articles based on the Walden standard, for example. In view of standard with the circle of 
qualitative method, a cursory or unattended practice of literature review is one most frequent cause that the researcher might do a faux-research.

For example, I may illustrate my case relating with the theory that constitutes the background and influence to deal with my inquiries for the PAKJS. In combination of grounded theory approach, the hermeneutics and heuristics will be employed that a complete exposure to the theory as well as reading and analyzing the texts and written materials of nonEnglish literature are dual horns to wheel ahead the stage of data analysis and through a write-up. Given an insufficient understanding of theory, my research will go astray as disabled without a proper placement within the epistemology or world of thought, or intellectual heritage. In my case, Foucault, Habermas, and Bourdieu are three of authorities that importantly influence the approach and manner of dealings in terms of epistemology and social constructivism as well as possibility of normative subscription or even ordering (Patton, 2014). Therefore, they generally govern how to study and guide to structure and frame the understanding and thought as constantly emerged through the data analysis, hermeneutics and heuristics. The three authorities generally resound as a leading post modern thinker, but with a little distinction among another. They are commonly referred as a humanist and sociologist that basically are philanthropic to have a potential of "discursive" through a wide discipline of humanity and social science (2014). As for the words and perception of Foucauldian flavor, he is most deconstructive for the power that holds a most extent of focus on epistemology than his social constructivism. He is, therefore, more richly viewed as linguistic scientist or psycho-analyst, which is very foundational that the qualitative research starts out. The power and knowledge are his consistent points of inquiry that the subjectivity would be any viable thesis in the end, meaning his crucial destination, i.e. subjects for the autonomy within the power relations. His ending query would be a selfconstitution that should be constructed within such power relations, in some cases, illusory state by Bourdieu and governmentality for himself (2014). As his works evinced, he employed a historical method to trace the humans of knowledge.[1] Habermas would be compassionate with Foucault's taste and philosophical approach that he also is concerned of the personal autonomy within the social mosaic of governmentality and influence. He, nevertheless, disagreed on his refusal to propose positive solutions for various social and political issues, in which the subscribers of Habermas criticized him as a cryptonormativist.[2] While the order of things or the kind of concepts, such as governmentality and impliedly over the state role can be discerned within the thought, his scholarship is critiqued that disregards the inevitability of power with human relations, and inescapably conditional freedom even as an ideal. Habermas, therefore, argues on the normativity as an ingredient of human elements as socially constructed and contingent, which the normativity arises from an "implied norm" - probably not of those as positive or expressive within the juridical science - since Habermas is sociological with the community and philosophical on humanity. Habermas, in this stance, seems more reliant on Enlightment thinkers that flavors on German rationalism and respect of order, which can compare with the more radical theory of critique. 
P. Bourdieu, another post-modern thinker, provides the epistemological and social understanding for the objects, in which we can borrow useful tools of analysis to deal with social constructionism beyond the Foucauldian epistemology and critical theory (Hamatiataya, 2015). He expounded many useful terms, concepts, themes and ideals, as well as thought frames that can influence the studies on PAKJS. For example, we plainly perceive that the human agents think, act, interact and process within a socially constructed value system. [3] His concept of a field provides a fit to look into the policy process, and action, process, and interaction of policy makers which happened within the PAKJS. In view of policy process, it often would be true that the agents and their social positions are located, (ii) with the specific rules of the field, (i) via interaction between the agents' habitus and capital (iii) hierarchically and with the relationship of subordination on the power and class relations amongst the fields. His elaboration on the cultural capital is useful to analyze the agenda settings of new law school system and decision making process to plan or implement through the on-going controversy (2015). In his frame, cultural capital is essentially intertwined with the development of capitalism and also is interconnected to form a social ego. The cultural capital is one ramification of social capital that refers to assets including, for example, competencies, skills, qualifications, which enables holders to mobilize cultural authority.[4] This concept lends a ground for the critiques of new law school system as it can also be a source of misrecognition and symbolic violence.

\section{One Article as a Best Use of Theory}

One article used the theory of Bourdieu to critique the American system of law school, which, I consider, would be a fine example explicating the social stratification and class hierarchy within the educational settings (Jewel, 2008). It is, in terms of my discussion content, has a good bearing that inspires the ways of thinking the legal education and attorney qualification. I believe that the mentality of Korean public is not the same with the western states because of long history of feudalism, same ethnicity and distinct culture to respect the paternity and Confucianism, and the kinds. One most instant effect relating with these distinctions would be no serious consciousness of class and social stratification, at least, in the initial stage of system building. Provided that Koreans are highly educated minds in terms of modern civilization and moral citizenship, but also with the qualities of generosity and social harmony as emphasized by Confucianism, the response for the policy issues, at least as involved with the reform toward US mode of legal education, are epistemological more than economic, and less intrusive by less seriously taking the socio-cultural and class consciousness from the economic terms. As enunciated, the policy makers and research taskforce often preferred the comparative studies among the key countries. While the policy disagreement and conflict of interested players had grown, the drift of public awareness increasingly had come to center around the intellectual heritage of state, meta-capital, habitus, and class hierarchy or social constructivism.[5] The points of critiquing in the article reveal any extent of same notion and sensibility concerning the law school system 
although the years of public experience about this new system actually are shorter in Korea. Therefore, it is closely relevant with my research, and also instructive how to use a theory to explicate and critique the American law school system.

The author begins his story by exemplifying a general point of view to explain (Writing a Support Services, 2015), in which he invited, "stratification has long existed within the American legal profession, and in many instances, status inequalities.... are based on perceived differences in attorney's educational credentials (Jewel, 2008)." 6 The article is structured clearly between the theory and research object that comprises four parts of essay. The first part provides a foundational summary of Bourdieu's theory. The second part explores applicability of theory to the American legal education in terms of its institutional structures and culture. The third part deals with a reflective critique by asking whether law teachers might be contributing to the status inequalities within the legal profession. The fourth part deals with the oppositional strategies and critical pedagogy (2008).

The article shows a good pathway beginning with the theory that social institutions, including educational institutions systemically replicate existing hierarchical structures within the modern democratic societies. The author, while recalled upon his time of attendance for the CLE course and lectures on the manner and style of attorneys as middle or upper class, introduced his need of class-based research concerning the status inequality and attorney qualification system (2008). His thought on income disparity and economic incongruence within the legal profession bears a similarity that not infrequently has been reported by mass media in Korea. He enticed the audience into the theme of symbolic capital by passing comparatively with the economic capital (purely concerned of resultant income disparity lacking a consideration of the relationship between the educational institutions and existing hierarchical structures) and power relations within the workplace (for example, between the attorneys of managerial capacity and hired ones). While he saw Bourdieu's works to span the disciplines of anthropology, sociology, education and history in the section "Sources Consulted," he introduced an attention of audience to a great amount of research into educational institutions in terms of role of institutional pedagogies, collective attitudes, and docile individuals (2008). He, then, emphasized a sociological frame to uncover and publicize the myths that lead to structural subordination with the caution not to ignore the objective view of hierarchical social structure and individual's conscious subjective view of herself. The next turn, as a way of logical process to constitute the theme of author, requires to weigh the moral aspect of Bourdieu's theories, in which he perceived it compelling and his position was clearly declared as of middle ground between the existing rules and mores for the ethics of attorney and critical awareness of these rules and mores masking hidden process that tend to reproduce institutional and societal structures (2008).

The structure and manner of presenting his studies on the theory are fine and straightforward allowing the audience the nature of theory that will be applied to his research 
object.[7] He illustrated major works that help to understand the theory, for example, "Weininger's foundations of Pierre Bourdieu's class analysis." He summarized succinctly the main ideas of theory that came, on plotline to deal with the purpose of article, to facilitate his discussion of research object. He churned on the types of capital,[8] valuing symbolic capital,[9] education and the reproduction of class structure,[10] and symbolic consumptiontaste, [11] and moral dimension[12] that would support his research purpose to critique the American legal education (2008). His use of theory to strip of the current practice of American legal education can make a good fit to encompass the tiered ranking system of law schools, prevailing attitude on the class rank in the privileged legal market, and bar examination as a final institution to qualify for the attorneys.[13] His application of theory to his research object are aligned persuasively to understand the hierarchical structure of legal profession, in which the idea of habitus as coupled with the myth of merit lends a good tool of analysis in terms of educational and social value (2008). In the part of moral dimension, the author posited to question if the research and legal scholarship is determinative of creating the hierarchical structure within the law school system. Then he proposed the need of an alternative way of legal education, for example, practice-based training for the individual client of low status law school students. He is a good user that was toned with the critical theory and raised a voice for the intact cultural group, i.e., low status law schools, and their students or professors by suggesting alternatives and actions through four aspects, including normative strategies and pedagogical strategies. For example, his argument is resounding, "as law teachers, we must do more than simply argue that the established order is wrong...we must also critique ourselves....the danger of silence is that it strengthens the habitus, making the institution a more fertile mechanism for reproducing existing inequalities - within our profession and within our society as a whole (2008)." While massively borrowing the ideas of Bourdieu in explicating his research object, it is interesting to taste a tacit influence from other post-modern thinkers, such as Habermas and Foucaut, thorough his deliberation of normative solution and structure of thought for the subjectivity within the power relations. 


\section{References}

Hamati-ataya, I. Bourdieu-in-the-making: on the state and the craft of reflexive sociology. Retrieved Dec. 12, 2015 from

https://www.academia.edu/17616618/Bourdieu-in-theMaking_On_the_State_and_the_Craft_of_Reflexive_Sociology_Forthcomin g.

Jewel, L.A. (2008). Bourdieu and American legal education: how law schools reproduce social stratification and class hierarchy, Buffalo L. Rev. Vol. 56, pp. 1155-1208.

Kim, Kiyoung, An Attempt on the Methodological Composure: Between the Number and Understanding, Nature and Construction (December 12, 2015a). K. Kim, An Attempt on the Methodological Composure: Between the Number and Understanding, Nature and Construction, Chosun University, 2015. Available at SSRN: $\underline{\text { https://ssrn.com/abstract }=2702701}$

Kim, Kiyoung and Ju, Hyun-Meong and Khatun, Marium, A Reflection on the Research Method and Exemplary Application to the College and University Rankings (October 23, 2015b). Kiyoung Kim, Hyun-Meong Ju, Marium Khatun. A Reflection on the Research Method and Exemplary Application to the College and University Rankings. Education Journal. Vol. 4, No. 5, 2015, pp. 250-262. doi: 10.11648/j.edu.20150405.23. Available at SSRN: https://ssrn.com/abstract=2686045

Kim, Kiyoung, Concerning the Research and Science (April 10, 2015c). Available at SSRN: https://ssrn.com/abstract=2592858 or http://dx.doi.org/10.2139/ssrn.2592858

Kim, Kiyoung, The Research Design and Methodologidal Deliberation (December 23, 2015d). Available at SSRN: https://ssrn.com/abstract $=3305760$

Patton, P. (2014). Foucault and strategic model of power, Critical Horizons, 15-1, pp.1417.

Randolph, J.J. (2009). A guide to writing the dissertation literature review. Practical Assessment, Research \& Evaluation, 14(13), pp. 1-13.

Writing a Support Services (University of Calgary). Writing a critique or review of a research article, Retrieved Dec. 11, 2015 from ucalgary.ca/ssc/writing-support.

[1] His work elaborated on the power and knowledge, as well as the archaeology of knowledge so that we can agree on his insight about humans. We may consider a human as economic or political as an essential element or ingredient, but less said of a "highbrow" in those qualities. In those qualities, humans are simply prurient and egoistic or beings of 
uncurbed thirst through struggles and domination. Therefore, his beginning point of approach often is said noble and the kind of "last bourgeois" which is elevated onto the social meaning that also must be indebted to the Bourdieu's concept, habitus. In this sense, Foucault's mentality can be interpreted that represents the epistemological dealings to respond with the agonies of "knowledgeable nobility" in the post-modern society (As similar to the epistemological agonies of $P u Y i$, the "last Emperor" of China and the twelfth and final ruler of the Qing dynasty). His historical method also is insightful to address his theme of knowledgeable subjects and power, as we read the history of madness. His account on the examination of history about the economic discourse also resounds to understand the interactions between the power and knowledge... His epistemological graveness may go beyond the social limits, as his colleague P. Bourdieu commented on his thought as a philosopher, "...... long exploration of transgression, of going beyond social limits, always inseparably linked to knowledge and power." Given the quality of his works, Foucault's discussions on power and discourse have inspired many critical theorists, through his analysis of power structures and struggles against inequality, and hierarchies legitimated by, but inconsistencies with the corresponding fields of knowledge. Imagine if the hierarchies are congressional or from the majority rule, but can be questioned and uncovered through the process of constitutional review, in which subjects may be redressed from his inequality. In this application, the theory may be used by legal scholars to analyze the justification of constitutional review system beyond the normative power of constitution, meaning its volatile utility through his discursiveness or power and discourse. Nevertheless, the exact definition for his use of key terms, e,g. "power" is not given that can have an extent of compass to arouse a contract and tension with the subjects, who are knowledgeable, hence noble and bourgeois, but epistemologically inculcated to apprehend the power relations. Then the personal autonomy or subjectivity for self government could be idealized.

[2] As similar, Diana Taylor and Nancy Fraser critiqued that Foucault denied traditional moral systems, such as freedom and justice, which brought his discourse lacking positive alternatives

[3] The kind of concepts and theories, e.g. habitus and doxa, are useful because the policy makers, individual agents or even philosophers generally dispose his dispositions -- formed between objectivism and subjectivism and resolved with the prominent antinomy of human sciences -- in response to the objective conditions it encounters unless he is superior as more knowledgeable to forge his divine or persuasive missionary. And in doxa, we can affirm the sociable person that he acts or interacts on the learned, fundamental, deep-founded, unconscious beliefs, and values, taken as self-evident universals. These qualities of social ego entail that inform an agents and thoughts within a particular field. 
[4][4] For example, the children of working class would be unconscious of his educational inequality and easily legitimate their educational success of upper-class peers. They misconceive them as naturally more capable or working hard with better results.

[5] The popularities in the community, such as powerful congressmen and ranked bureucrats, not infrequently were cited by the mass media that they exercised an influence of their position and social prestige in the admission process and recruitment of new attorneys by the high salaried law firms. The tendency from pure epistemology toward corruption or public distrust shows that the practice is more important than system or institution and that social pathology offers a moment for sociological minds and social constructionism, as exemplified of the increasing suicides for Durkheim's sociology, and dormant middle class absent minded with the meta-capital or class hierarchy.

[6] A way of approach for the subject matter may vary with the stance of authors in addition to that of this article, (i) observing and identifying objects for analysis (ii) describing features, (iii) defining, referring, classifying, distinguishing, or comparing terms (iv) theorizing about or explaining why things are the way they are (v) conjecturing or speculating about explanations (vi) evaluating the adequacy of our observations.

[7] For example, he added a footnote frequently to support his arguments, and cited a paragraph in any due style that has an indented replication. See, for example, pp 13-14.

[8] According to Bourdieu, the author argued that the first and most important factor bearing on one's class status is the volume of capital that a person has, and that a person can hold different types of capital, in which each type is valuable in determining one's social class. While the different types of capital include economic, cultural and social, they would have a trade-offs effect to produce a conclusive person of particular social class.

[9] His deals take a good shape of introduction to provide the core of Bourdieu's frame and thought that three concepts, including the habitus, objectification and symbolic violence, can explain the process of internalizing the class structures and their replication by the members of a society. Beyond the education or legal education, the author also consulted with the common law and civil law traditions, and legal practice of judges and lawyers. He leaned on the proposition of symbolic violence, "the reproduction of the established order by its own motion... by maintaining a logical and aristocratic detachment, lawyers and judges are able to maintain the symbolic value of the law....obscuring the fact that the law allows powerful groups to impose their vision of social order on the less powerful..."

[10] His adherence with the concept of symbolic violence is relevant with his research topic by expounding the idea of Bourdieu's, "educators teach in a way that mirrors the dominant culture in a way that is sanctioned by the dominant culture....In France, teachers must use 
university language, the abstract and detached language of the upper class, or lose authority..." The author also illustrated the linguistic capital, in which the student exposed to complex language transmitted by her family will excel the other students of different family background, and importantly schools mask the importance of inherited cultural capital.

[11] The author discussed a creation of individual class identities through the consumption of goods, in which the social hierarchy or privilege is expressed through lifestyle (distinction v. vulgarity, legitimate manners, highly censored language and slow gestures, and successful bluff, for example.

[12] The author is well-intentioned to deal with the moral dimension of Bourdieu's theory, in which the academics and intellectuals have a moral duty to uncover and demystify the myths of institutional domination. He was particularized to share the possibility that the changing and questioning of values can transform the world. For him and Bourdieu, two paradoxes arise, including the liar's paradox and conflict of participant's subjective understanding with the class structures of symbolic violence. The impression of symbolic violence for Bourdieu was expressed as cultural and on the consumption. The audience also may generate an imagery of feudal aristocracy, such as duke and prince, who were armored in readiness to combat for defending their prestige and social hierarchy. This imagery may reincarnate within the minds of prospective clients when they seek better attorneys or more efficient law firms in terms of the meta-capital.

[13] For example, the insidious process of excluding unsuccessful bar applicants from entering the legal profession can be explained in terms of "status closure theory" and interest of the hierarchical class to control the number of attorneys. In the same way, the prestigious law schools do not prefer to weaken their commitment to raise credentialed experts because of the cultural capital that they have amassed. 